\title{
SOCIAL INTEGRATION OF PEOPLE WITH DISABILITIES IN THE FIELD OF SPORT
}

\author{
Albena Dimitrova
}

Modern civilized societies are based on the principles of humanism and democracy. The center of public interest is the person - a unique person with his rights and responsibilities. People are born different but with equal rights. Public attitudes towards the disabled are part of the human and social norms that characterize the free, civil society. In the value system designed to improve this category of people, physical culture and sport occupy a definite and essential place. Activities with adapted physical activity contribute significantly to speeding up the recreational and integration process of children with disabilities in society.

The aim of the research is to reveal some problems related to the social integration of people with disabilities and the role of sport in improving their quality of life. The purpose of this paper is to enhance the theoretical and practical knowledge of real and potential users (specialists, students, people involved in sport).

Methodology: study of literary sources and content analysis.

Conclusion: The dispute is a social phenomenon that has a positive influence on the education of society in the ideas of humanism and fights against prejudices and stereotypes in this category of people.

Key words: social integration, sociology, people with disabilities, sport.

\section{Introduction}

Sport for people with disabilities is not a new concept, but its full potential as a powerful, low-cost means to foster inclusion and well-being of disabled people has begun to be realized.

The sociological indicators which have been used for defining disability and addressing the issue in question are as follows:

“- possibilities to fulfill social roles,

- possibilities for interpersonal communication,

- possibilities for basic daily activities" (eg. Ikov, 2014).

Sociologists could also usefully apply the concepts of role and status to disability. The role of "people with disabilities" is similar to, and at the same time different from other roles which have not been fully delineated yet. Its influence on other roles such as wife and mother have not been fully explored yet. A paper which date back from the past did consider the question of disability and role (Thomas, 1966), but both its terminology and its conceptualization of disability have been outdated. Sociologists have not considered the question of whether or not disability is a main status, and, if so, how it compares to other main statuses such as race and gender, although Barnartt (2001) made a start at such analyses (eg. Barnartt, 2005).
In particular, they can be interpreted from the point of view of the main categories of life: "possibilities for: self-service; self-moving; education; work; orientation in time and space; communication (establishment of contacts between people, processing and transmission of information); control of their own behavior, etc. “(eg. Ivkov, 2014).

If disability has been considered by the concept of the rights of disabled people, it could have been affirmed that these restrictions are based on the person's difficulties in realizing and protecting his / her rights - civil, social, economic, etc.

\section{Hypotheses:}

$\checkmark \quad$ I assume that various issues related to the social integration of people with disabilities on national and global scale will be recorded at the end of the survey;

$\checkmark$ I assume that adapted physical activity, including sport and its different elements, will contribute to adequate social integration of the people with disabilities and to the improvement of their quality of life.

The aim of the research is to reveal some problems related to the social integration of people with disabilities and the role of sport in improving their quality of life. 
The aim of the present publication is to enhance the theoretical and practical knowledge of real and potential users (specialists, students, people with respect to sport).

For realization of the research the following objectives are outlined:

$>$ to study literary sources related to the problem;

$>$ to outline and analyze the people's needs for adapted physical activity and social integration of people with disabilities;

$>$ to reveal and analyze the main interrelations between the social integration of people with disabilities and the role of sport in improving their quality of life.

Methodology of the research: study of literary sources and content analysis.

Organization of the conducted tests: 02.04.- 28.07. 2017.

\section{Discussion}

The social model of disability distinguishes between impairments and the disabling practices of society which prevent people with impairments from fully participating in social life. Shakespeare and Watson question the extent to which the social model can make invisible the experiences of impairment, which is to ignore a large part of people's lives. Research has shown that many people with 'impairments' prefer to be identified as 'ill' rather than 'disabled'. This is perhaps not surprising, as 'disabled' is a stigmatized identity. The example of Cherubism is presented as an example of the relationship between stigma and disability.

Whilst the impairment/disability distinction has been politically useful for disability rights campaigners, medical sociologists criticize the distinction, as both are social constructs (eg. Giddens, Sutton, 2013).

The use of social factors to explain community health status is not a new phenomenon. Since Durkheim's classic work on suicide, the importance of social integration and social capital has been recognised for people well-being (eg. Durkheim, 1951).

Today there are needs for concrete practical actions to ensure conditions to create equal chances for a complete activity for people with disabilities (eg. Stoeva, Kostadinova, 2004; Mladenova, 2014). This means equal rights, equal opportunities, equal responsibilities for all members of society. The rules for equal participation cover all spheres of public life. One of the priorities for overall formation is education and physical activity. The dispute, as one of the major social institutes in society, has a unique nature and performs various functions such as: educational, health respectable, social, cultural and recreational (eg. Nikolova, 2009).

Integration could be realized in many ways and forms. One of them is the adapted physical activity, which is an important factor for beneficial impact. Good opportunities for physical strengthening, development of motor skills and habits, psychological, social and spiritual development have been created through the application of adapted physical activities according to V. Aleksandrova (eg. Alexandrova, 2013).

Contemporary tendencies require the inclusion of adapted physical activity including sports and elements of various sports (skiing, rowing, swimming, horse riding, ice skating, car rallies with adapted cars and others) in complex rehabilitation as a curative, preventative and sporting tool (eg. Vultchev et al., 2014).

The CONNECT project in Australia has led to the inclusion of people with disabilities in a wide variety of national sports organizations covering the following sports: athletics, basketball, swimming, tennis, bowling, yachting, baseball, softball, surfing, table tennis, cricket, golf, bowling, and riding. It also attracts and retains people with disabilities in a variety of sports roles: volunteer, spectator, administrator, player, and coach.

The use of the sporting potential for SOCIAL INCLUSION, integration and equal opportunities has had an important contribution to economic and social cohesion. It is therefore necessary to take into account the specific needs and situation of the under-represented groups and to pay attention to the special role of sport for young people, people with disabilities and disadvantaged socio-economic backgrounds. Sports must be accessible to all categories of people.

"The principle of equal participation of all people, 
independently from gender, ethnicity, religion, social status, physical and intellectual development, has been respected during one year's work in the clubs and during the Fairs. In the "Yunache" clubs are accepted all children - weak, fat, regardless of physical and intellectual development, children from ethnic groups. Promoting social inclusion and cohesion, enshrined in the Olympic principles and in European documents " (eg. Vladova, 2015).

Fotev believes that social integration is realized in multiple social interactions, the necessity of which is normative in terms of the whole. Basic solidarity between individual and collective agents, as well as the sharing of main values, and especially social values, is needed to maintain (eg. Fotev, 2004).

Social integration, according to T. Parsons, can be divided into normative and valuable, which is truly related to the sport as social institute (eg. Parsons, 1998). The values that are transmitted through sport help to develop the knowledge, motivation, skills and readiness to make personal efforts. The time spent in sports activities has a beneficial impact on health and education, and this impact needs to be increased. Sport enhances human capital through its role in formal and non-formal education.

The integration has been considered as the development of common activities and initiatives between different countries, the organization of multinational projects through cooperation, interaction, exchange of experience, information as well as positive examples and practices in different social spheres and joint activities, according to Ekholm (eg. Ekholm, 2006; Slavova, 2016).

Sport for people with disabilities "aims to improve the quality of life, rehabilitation and social integration, providing the necessary conditions for practicing various sports" (eg, Dimitrov, 2016; Fay, Wolff, 2009).

Integration and inclusion of people with disabilities into regular sports events has been a major focus in recent decades and creates new opportunities for participation and competition.

Three biggest international sport competitions for people with disabilities are the following:

$>$ Special Olympics (for athletes with intellectual disabilities) - provides opportunities for training and competitions throughout the year; $>$ Paralympic Games (for athletes with different degrees of physical disabilities) - six different groups of athletes with physical disabilities; $>$ Deaflympics (for hearing impaired athletes).

The number of international organizations and associations serving athletes with disabilities has increased dramatically. In some countries, there are more opportunities for people with disabilities to participate in school sports events, clubs and various kinds of sports activities in the community.

At local level, the program for the development of important organizations such as "Handicap International" has enabled thousands of people with disabilities in developing countries to become active in sport and physical activity.

Touring competitions in other cities and countries, receiving first prizes, sports victories have allowed active integration, acquisition of models and types of behavior, etc.

All competitions increased in quantity, new sports bases, the training process organized abroad, have created new values and orientations. A major role in the socialization stage has been played by the economic relationships that develop between athletes and coaches.

The National Assembly of Bulgaria has ratified the UN Convention on the Rights of People with Disabilities on 26 of January 2012. Our country has taken small steps towards integrating people with disabilities into and through sport. It sets out different strategies and principles that have safeguarded the rights of people with disabilities, as well as provided more opportunities for equality, full inclusion in society, accessibility, etc. (eg, United Nations Convention of Rights of people with disabilities, 2012).

Practicing sports facilitates social integration and fosters cultural dialogue. In view of this, it is important to provide sport facilities and support sports activities.

Sport enhances the shared sense of belonging and empathy and can therefore be an important tool for integration. 


\section{Conclusion:}

The quality analysis of the data has revealed that the hypotheses have been confirmed.

Physical activity as a result of participation in sports events contribute to an improvement in the functional status and quality of life of people with disabilities, related to improving self-esteem and social sensitivity.

Sport works to improve the inclusion and well-being of people with disabilities in two ways - by changing the point of view of communities about people with disabilities and by changing the point of view of people with disabilities about themselves. The first is necessary to reduce the stigma and discrimination associated with disability. The second empowers people with disabilities so that they recognize their own potential and opt for changes in society. The community impact and individual impact of sport help reduce the isolation of people with disabilities and integrate them more successfully into community life.

\section{Literature}

Alexandrova, V. (2013), „Adapted physical activity and skating for children with autism ", Journal of Sport and science, 1, pp. 124.

Vladova, I. (2015), Olympic children's fair „Yunache“sport pedagogical model for education and training. Doctoral thesis, NSA, Sofia, pp. 110.

Vultchev, V., Nikolova, M., Rankov, K., Alexieva, D. (2014), „Research of frequency of inguinal epidermophitia and tinea pedis for athletes", On some actual problems of physical education and sport, Collection. NSA „Vassil Levski“, Sofia, pp. 98.

Dimitrov, V. (2016), Sport law, NSA Press, Sofia.

Ivkov, B. (2014), Sociology of handicap, Omda, Sofia.

Karanechev, G. (1983), Theory and methods of curative physical education, Medicine and Physical education, Sofia.

United Nations Convention of Rights of people with disabilities, (2012), available at: http://www.un.org/disabilities (accessed on 12 April 2016).
Nikolova, M. (2009), Social and educational integration of people with disabilities through adapted physical activity and sport, NSA PRESS, Sofia, pp. 33-34.

Slavova, V. (2016), „Study of attitudes of children and youth towards implementation of new technologies in sport training ", scientific conference "Challenges and perspectives for sport science“, „Specifics of preparation in different sports disciplines", NSA PRESS, Sofia, pp. 195.

Stoeva, B., Kostadinova, V. (2004), Group for European prognosis and researches (GEPR), People with disabilities and their rights in European Union, Bulgaria and its "invisible" citizens; Main problems of people with disabilities. Sofia, available at: http://www.osf.bg/cyeds/ downloads/euro gepi 7.pdf (accessed on 07 March 2016).

Fotev, G. (2004), Dialogical sociology, East -West, Sofia, pp. 463-479.

Parsons, T. (1998), System of contemporary societies. M. Barnartt, S. (2005), Report of the ASA Committee on the Status of Persons with Disabilities (PWD) January, By haron $1 \mathrm{PhD}$, Gallaudet University.

Ekholm, L. (2006), The Bologna Process 1999-2006, and beyond, ERASMUS - contact seminar, March 8, 2006, Stockholm.

DePauw, K., Gavron, S. (1995), Disability and Sport, Human Kinetics, Illinois.

Durkheim, E: Suicide: a study in sociology Edited by: Simpson G, Spaulding JA, Simpson G 1951. New York: Free Press; 1897.

Fay, T., Wolff, E. (2009), „Disability in sport in the twenty-first century: creating a new sport opportunity spectrum", Boston University International, Law journal, Vol. 27, pp. 230-248.

Giddens, A., Sutton, P. (2013), Sociology, 7th Revised edition, Polity Press, Chapter Health, Illness and Disability, pp. 93-101.

Mladenova, S. (2014), „Safety possibilities, socialization, and integration of people with disabilities", Journal of International Scientific Publications, Vol. 12, available at: www.scientific-publications.net (accessed 12 May 2016). Yakkaldevi, A. (2014), The sociology of disability, Volume 2, Issue 3. ISSN:-2347-2723.

ass.prof. Albena Dimitrova, Ph.D. Sofia 1700, Bulgaria, Studentski grad, NSA „Vassil Levski“, Department of Psychology, pedagogy and sociology tel.: (02) 4014 (373) www.nsa.bg GSM: +359893393370 e-mail: albena234@ abv.bg 